\title{
Effectiveness of Intraluminal Air Decompression on Postcolonoscopic Pain According to Reinsertion Site
}

\author{
Young-Jin Sur, Jung-Hyun Kim*, Seung-Jin Jung, Dong-Won Lee, Sang-Hyun Cho, Ryang-Pyo Kim, Tae-Wan Kim, \\ Hyeon-Guk Shin, A-Ram Hong, Hyun-Woo Kwon \\ Department of Family Medicine, Hana General Hospital, Cheongju, Korea
}

\begin{abstract}
Background: Colonoscopy is a very effective and essential examination to diagnose colorectal cancer; however, many patients experience discomfort due to post-examination abdominal pain, which reduces colonoscopy compliance. This study was conducted to determine methods for reducing post-colonoscopic abdominal pain. Methods: We conducted a randomized controlled study of 405 male and female adults who visited Hana General Hospital in Cheongju. We surveyed general characteristics, history of colonoscopy, and other related factors, then categorized examinees into 5 groups (0-5) according to the site of scope reinsertion. Pain was measured using a numeric rating scale (NRS).

Results: The mean age of examinees in this study was 47.8 years, and 210 participants had prior experience of colonoscopy. No significant difference was observed between variables, with the exception of reinsertion duration $(\mathrm{P}=0.005)$. Pain scores were different between performing physicians $(\mathrm{P}=0.006)$, and were higher when the subjective level of procedure difficulty was low $(\mathrm{P}=0.026)$ in univariate analysis. Pain scores decreased as the reinsertion site became closer to the proximal colon $(\mathrm{P}<0.001)$, but there was no significant difference between groups 3 and 4 . The results of multiple logistic regression analysis, including univariate analysis, showed that group 1 had 0.48 times, group 2 had 0.38 times, group 3 had 0.09 times, and group 4 had 0.03 times odds ratio (moderate-to-severe pain, NRS $\geq 4$ ) than control group 0 .

Conclusion: Air decompression by scope reinsertion is an effective way to reduce abdominal pain after colonoscopy. Removing air when the reinserted scope approaches the hepatic flexure seems to be the most effective method to reduce post-colonoscopic pain.
\end{abstract}

Keywords: Colonoscopy; Pain; Colonoscopic; Decompression 


\section{INTRODUCTION}

In Korea, annual colon cancer incidence has averaged 5.2\% since 1999 and has increased steadily, although incidence rates vary between men and women. ${ }^{1,2)}$ Accordingly, the importance of early detection of colorectal cancer by colonoscopy, especially in high-risk patients, is well known. ${ }^{3-6)}$ However, pain after colonoscopy is a major patient complaint, and this is believed to cause reduced compliance with follow-up. ${ }^{7,8)}$

There have been several efforts to identify the cause of abdominal pain after a colonoscopy, including a study by Lee et al. ${ }^{9)}$ in which the sex of the patient and the duration of the examination were found to be the main causes of pain. The majority of recent studies report the main cause of post-colonoscopy abdominal pain to be stimulus of unmyelinated $\mathrm{C}$ fibers by abdominal distention caused by intestinal gas; therefore, decompression may reduce pain and discomfort after the procedure. In prior studies of air decompression, procedures using carbon dioxide were found to reduce patients' pain and the frequency of toilet use after colonoscopy. ${ }^{10-13)}$ However, studies of air decompression by scope reinsertion did not control for factors that are thought to affect pain after colonoscopy, such as bowel preparation state, medication, and additional procedures; moreover, studies with different reinsertion sites do not show consistent results. ${ }^{14-16)}$ Therefore, this study was conducted to increase compliance with colonoscopy guidelines by investigating whether decompression by scope reinsertion after colonoscopy can affect abdominal pain, and whether pain varies with reinsertion site.

\section{METHODS}

\section{Subjects}

This study targeted all adults aged 21 or older visiting a hospital in Cheongju for a health check-up between December 5th, 2014 and January 10th, 2015, whose conditions did not contraindicate colonoscopy and who consented to participate in this study. All participants agreed to the use of their information in this research and gave written consent after being informed of the purpose of this study.

\section{Pre-Examination Survey: General Characteristics and Past Medical History}

Participants completed questionnaires to self-report present medication, past abdominal and pelvic surgical history, history of pelvic inflammatory disease, and history of colonoscopy. Irritable bowel syndrome was evaluated using the Rome III criteria, by asking patients whether they had experienced abdominal pain, diarrhea, and constipation for 3 months without any other known cause.

\section{Colonoscopy and Patient Groups}

Colonoscopy was performed by 3 family medicine specialists who had performed over 5,000 cases. Results were recorded by the performer immediately after the colonoscopy. Results included the physician's name and signature, subjective level of procedure difficulty (good, fair, or poor), cleanliness of the intestine (good, moderate, or poor), and additional procedures performed during the examination (e.g., polypectomy, biopsy, control of hemorrhage). Subjects were randomly assigned to one of 5 groups in which the tip of scope was inserted to different points to decompress air after the examination: (1) group 0 , no reinsertion was performed for decompression; (2) group 1, scope was reinserted to the distal sigmoid, past the rectosigmoidal transition area; (3) group 2, scope was reinserted before the splenic flexure in the descending colon; (4) group 3, scope was reinserted before the hepatic flexure in the transverse colon; and (5) group 4, scope was reinserted at the cecum.

Subjects were grouped after all observation was complete and decompression was the only remaining consideration, so all procedures could remain double-blinded. Randomization was performed as follows: just prior to scope reinsertion, the assistant picked a random ticket numbered 0 to 4 and informed the performer of the selected number so the scope could be reinserted to the indicated location. Decompression was performed by reinserting the scope from the rectum to the indicated proximal location after completion of the observation process, but before the scope was removed. When the scope reached the indicated location, the performer suctioned the air and collected the scope. The procedure ended when the scope reached the anus (Figure 1).

\section{Evaluation of Pain}

Pain severity was surveyed using an 11-point numeric rating scale (NRS). ${ }^{17-20)}$ After 30 minutes from finish of anesthesia, examinees were asked how much it hurts at the information desk. Zero points indicated no pain, and above 4 indicated moderate or severe pain. If examinees returned home before being asked about their pain, they were called within 24 hours after the end of the examination.

\section{Post-Investigation Using a Picture Archiving and Communication System}

Post-investigation was conducted on an examination about duration of examination and whether the examination was complete or not, by using picture archiving and communication system (PACS). Total duration of the colonoscopy was estimated based on the time input in the PACS, using the input time of the first picture taken before insertion of the scope into the anus; the pictures taken during insertion, observation, reinsertion, and air absorption; and the pictures taken in the rectum and anus immediately before removal of the scope from the intestine. The time between the first and last pictures was presumed to be the total duration of the exam. Time was converted to seconds.

\section{Analysis and Statistics}

For general characteristics of all subjects and reinsertion groups, continuous variables were presented as averages and standard deviations, and categorical variables were presented as absolute numbers and percentages. We conducted comparative analysis by one-way analysis 


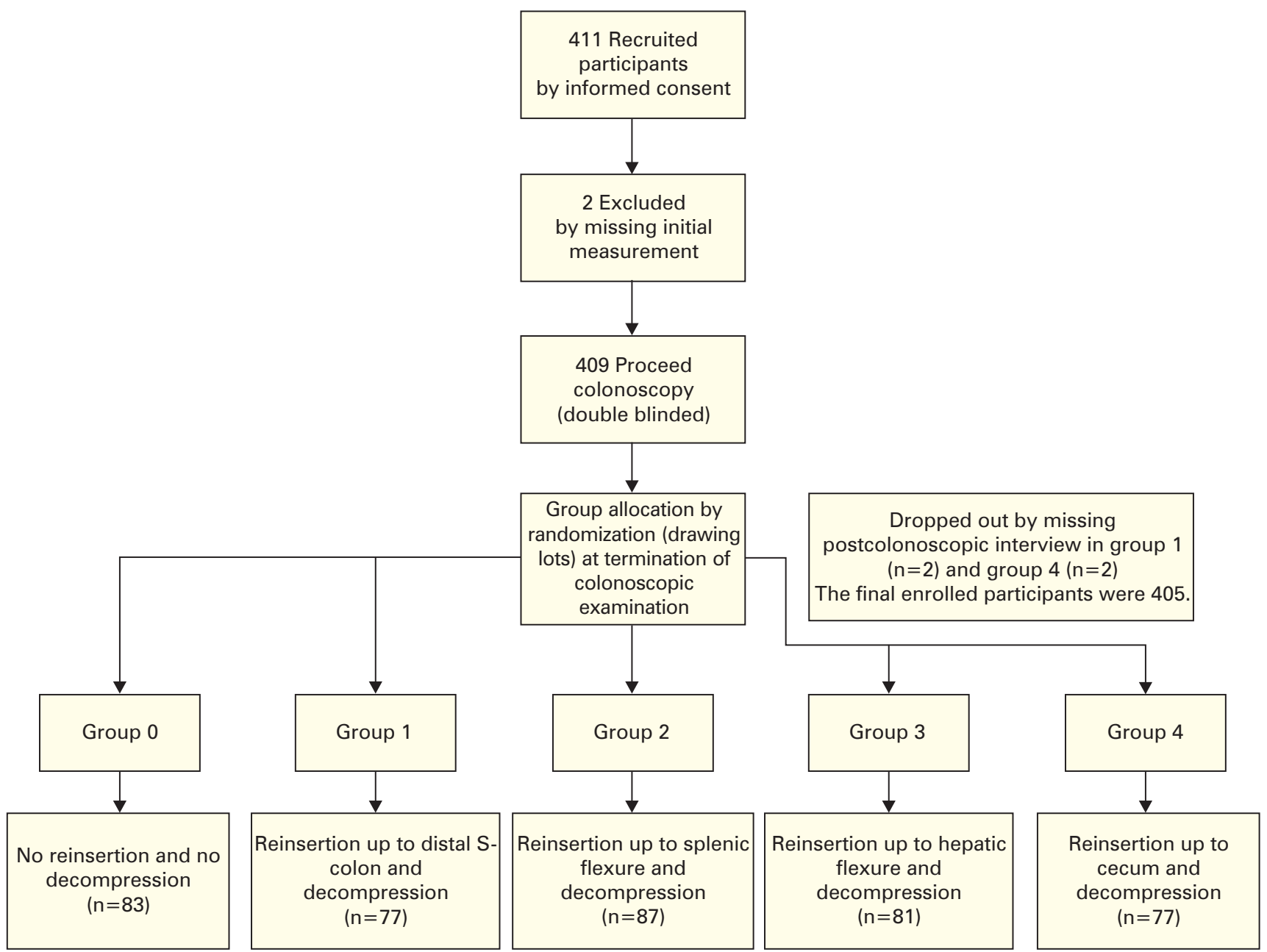

Figure 1. Flow chart of participants and study process.

of variance (ANOVA) for continuous variables, and by chi-square test for categorical variables when comparing general characteristics between the 5 groups divided on the basis of reinsertion locations. We presented the independent variable of NRS as averages and standard variations. NRS scores after colonoscopy were compared depending on general characteristics, several procedure factors, and reinsertion sites. An one-way ANOVA was used when there were more than 3 independent variables in the group, and an independent samples t-test was used when there were fewer than 2 . When the independent variables were continuous, we analyzed correlation using the Pearson correlation test. For variables that showed statistically significant difference and those that were thought to influence pain levels, we performed multivariate analysis through binary logistic regression. To analyze the relationship between reinsertion site and moderate-to-severe pain, we used a linear-by-linear association chi-square test. Statistical analysis was performed using SPSS ver. 15.0 software (SPSS Inc., Chicago, IL, USA), and $\mathrm{P}<0.05$ was used to indicate statistical significance.

\section{RESULTS}

A total of 411 individuals participated in the study after signing the consent form; of these, 405 were included in the final study. Two individuals were excluded from the study who did not have exact information (weight \& height), and 4 were excluded because they returned home early and contact was lost; thus, their pain was not assessed.

\section{General Characteristics of Participants}

The participant group included 247 men and 158 women with a mean age of 47.8 years. Of these, $186(61.6 \%)$ had a normal body mass index (BMI), 3 (1.0\%) had low body weight, 99 (32.8\%) were overweight, and $14(4.6 \%)$ were obese (BMI $\geq 30.0)$; mean BMI was 24.3 . Sixteen people (4.0\%) had irritable bowel symptoms, 12 (3.0\%) had a history of past abdominal operation, and 210 (51.9\%) had a history of past colonoscopy. Three physicians participated during the study period, performing 138 (34.1\%), 125 (30.9\%), and 142 (35.1\%) procedures, respectively. Bowel preparation was poor enough to affect the results in 170 cases (42.0\%). Procedure difficulty was classified as easy, moderate, and 
Table 1. General characteristics of study subjects

\begin{tabular}{|c|c|c|c|c|c|c|c|}
\hline Characteristic & Total & Group 0 & Group 1 & Group 2 & Group 3 & Group 4 & P-value ${ }^{*}$ \\
\hline Total & 405 (100.0) & $83(20.5)$ & $77(19.0)$ & 87 (21.5) & $81(20.0)$ & $77(19.0)$ & \\
\hline Age (y) & $47.77 \pm 9.78$ & $46.88 \pm 10.52$ & $47.60 \pm 10.22$ & $49.74 \pm 9.08$ & $46.95 \pm 9.35$ & $47.55 \pm 9.68$ & 0.306 \\
\hline Sex & & & & & & & 0.097 \\
\hline Male & $247(61.0)$ & $55(66.3)$ & $43(55.8)$ & $44(50.6)$ & $53(65.4)$ & $52(67.5)$ & \\
\hline Female & $158(39.0)$ & $28(33.7)$ & 34 (44.2) & $43(49.4)$ & $28(34.6)$ & $25(32.5)$ & \\
\hline \multicolumn{8}{|l|}{ Body mass index $\left(\mathrm{kg} / \mathrm{m}^{2}\right)$} \\
\hline Mean & $24.28 \pm 3.22$ & $24.19 \pm 3.80$ & $24.20 \pm 2.98$ & $24.26 \pm 2.47$ & $24.70 \pm 3.75$ & $24.08 \pm 3.03$ & 0.869 \\
\hline$<18$ & $3(1.0)$ & $2(3.1)$ & 0 & 0 & 0 & $1(1.7)$ & 0.582 \\
\hline$\geq 18,<25$ & $186(61.6)$ & $39(60.9)$ & 34 (58.6) & $44(67.7)$ & $32(56.1)$ & 37 (63.8) & \\
\hline$\geq 25,<30$ & 99 (32.8) & $20(31.3)$ & $22(37.9)$ & $20(30.8)$ & $20(35.1)$ & $17(29.3)$ & \\
\hline$\geq 30$ & $14(4.6)$ & $3(4.7)$ & $2(3.4)$ & $1(1.5)$ & $5(8.8)$ & $3(5.2)$ & \\
\hline Irritable bowel symptoms & & & & & & & 0.269 \\
\hline No & $389(96.0)$ & $81(97.6)$ & 71 (92.2) & $83(95.4)$ & 80 (98.8) & 74 (96.1) & \\
\hline Yes & $16(4.0)$ & $2(2.4)$ & $6(7.8)$ & $4(4.6)$ & $1(1.2)$ & $3(3.9)$ & \\
\hline Gastrointestinal medication & & & & & & & 0.173 \\
\hline No & $397(98.0)$ & $81(97.6)$ & $73(94.8)$ & $87(100.0)$ & $80(98.8)$ & 76 (98.7) & \\
\hline Yes & $8(2.0)$ & $2(2.4)$ & $4(5.2)$ & 0 & $1(1.2)$ & $1(1.3)$ & \\
\hline Current other medication & & & & & & & 0.856 \\
\hline No & $313(77.3)$ & 66 (79.5) & $57(74.0)$ & $65(74.7)$ & $64(79.0)$ & $61(79.2)$ & \\
\hline Yes & $92(22.7)$ & $17(20.5)$ & $20(26.0)$ & $22(25.3)$ & $17(21.0)$ & $16(20.8)$ & \\
\hline Abdominal operation history & & & & & & & 0.158 \\
\hline No & $393(97.0)$ & $78(94.0)$ & $76(98.7)$ & $86(98.9)$ & $80(98.8)$ & 73 (94.8) & \\
\hline Yes & $12(3.0)$ & $5(6.0)$ & $1(1.3)$ & $1(1.1)$ & $1(1.2)$ & $4(5.2)$ & \\
\hline Pelvic inflammatory disease history & & & & & & & 0.421 \\
\hline No & $404(99.8)$ & $82(98.8)$ & $77(100.0)$ & $87(100.0)$ & $81(100.0)$ & $77(100.0)$ & \\
\hline Yes & $1(0.2)$ & $1(1.2)$ & 0 & 0 & 0 & 0 & \\
\hline Past colonscopy history & & & & & & & 0.665 \\
\hline No & $195(48.1)$ & $36(43.4)$ & 41 (53.2) & 39 (44.8) & 39 (48.1) & 40 (51.9) & \\
\hline Yes & $210(51.9)$ & 47 (56.6) & $36(46.8)$ & 48 (55.2) & $42(51.9)$ & 37 (48.1) & \\
\hline Physician & & & & & & & 0.157 \\
\hline$A$ & $138(34.1)$ & 29 (34.9) & 24 (31.2) & 27 (31.0) & $23(28.4)$ & 35 (45.5) & \\
\hline B & $125(30.9)$ & $31(37.3)$ & $24(31.2)$ & $30(34.5)$ & $21(25.9)$ & $19(24.7)$ & \\
\hline C & $142(35.1)$ & $23(27.7)$ & $29(37.7)$ & 30 (34.5) & $37(45.7)$ & 23 (29.9) & \\
\hline Bowel preparation & & & & & & & 0.492 \\
\hline Good & $235(58.0)$ & $53(63.9)$ & $42(54.5)$ & $50(57.5)$ & $42(51.9)$ & 48 (62.3) & \\
\hline Poor & $170(42.0)$ & $30(36.1)$ & 35 (45.5) & 37 (42.5) & 39 (48.1) & $29(37.7)$ & \\
\hline Difficulty & & & & & & & 0.475 \\
\hline Easy & $195(48.1)$ & 37 (44.6) & 45 (58.4) & 44 (50.6) & 37 (45.7) & 32 (41.6) & \\
\hline Moderate & $174(43.0)$ & 40 (48.2) & $28(36.4)$ & 33 (37.9) & $36(44.4)$ & 37 (48.1) & \\
\hline Hard & $36(8.9)$ & $6(7.2)$ & $4(5.2)$ & $10(11.5)$ & $8(9.9)$ & $8(10.4)$ & \\
\hline \multicolumn{8}{|l|}{ Duration (s) } \\
\hline Mean & $455.32 \pm 223.78$ & $421.82 \pm 176.05$ & $401.92 \pm 196.71$ & $450.08 \pm 192.64$ & $480.85 \pm 252.61$ & $523.84 \pm 274.12$ & 0.005 \\
\hline$\leq 7 \mathrm{~min}$ & $232(57.4)$ & $50(60.2)$ & 55 (71.4) & 48 (55.8) & 41 (50.6) & 38 (49.4) & 0.038 \\
\hline$>7 \mathrm{~min}$ & $172(42.6)$ & 33 (39.8) & $22(28.6)$ & 38 (44.2) & $40(49.4)$ & 39 (50.6) & \\
\hline Cooperation & & & & & & & 0.421 \\
\hline Good & 404 (99.8) & 82 (98.8) & $77(100.0)$ & $87(100.0)$ & $81(100.0)$ & $77(100.0)$ & \\
\hline Poor & $1(0.2)$ & $1(1.2)$ & 0 & 0 & 0 & 0 & \\
\hline Additional procedure & & & & & & & 0.096 \\
\hline No & $281(69.4)$ & 61 (73.5) & 57 (74.0) & 65 (74.7) & $47(58.0)$ & 51 (66.2) & \\
\hline Yes & $124(30.6)$ & 22 (26.5) & $20(26.0)$ & $22(25.3)$ & $34(42.0)$ & 26 (33.8) & \\
\hline Premedication & & & & & & & 0.039 \\
\hline No & $6(1.5)$ & 0 & $2(2.6)$ & $4(4.6)$ & 0 & 0 & \\
\hline Yes & 399 (98.5) & $83(100.0)$ & 75 (97.4) & $83(95.4)$ & $81(100.0)$ & 77 (100.0) & \\
\hline
\end{tabular}

Values are presented as mean \pm standard deviation for continuous variables or number (\%) for binary variables.

${ }^{*}$ Calculated by one-way analysis of variance for continuous variables and by chi-square test for binary variables. 
hard in 35 (8.9\%), 174 (43.0\%), and 195 (48.1\%) cases, respectively. The mean examination duration was 455.3 seconds, and 124 cases (30.6\%) had further procedures such as polypectomy, biopsy, and clipping.

Groups 0 through 5 contained 83 (20.5\%), 77 (19.0\%), 87 (21.5\%), 81 (20.0\%), and 77 (19.0\%) participants, respectively. Most variables were not significantly different between groups; however, examination time varied significantly depending on the reinsertion group $(\mathrm{P}=0.005)$. The numbers of untreated premedication (like anti-spasmodics) were also different between groups, but there were minor (Table 1).

Table 2. Comparison of post-colonoscopic pain scale (numeric rating scale) by variables

\begin{tabular}{|c|c|c|c|c|}
\hline Variable & Value & Mean pain score & Correlation coefficient & P-value \\
\hline Age (y) & $47.77 \pm 9.78$ & & -0.116 & $0.019^{*}$ \\
\hline \multicolumn{5}{|l|}{ Gender } \\
\hline Male & $247(61.0)$ & 2.84 & & $0.353^{\dagger}$ \\
\hline Female & $158(39.0)$ & 3.06 & & \\
\hline \multicolumn{5}{|l|}{ Body mass index (kg/m²) } \\
\hline Mean & $24.28 \pm 3.22$ & & 0.066 & $0.256^{*}$ \\
\hline$<18$ & $3(1.0)$ & 3.33 & & $0.346^{\ddagger}$ \\
\hline$\geq 18,<25$ & $186(61.6)$ & 2.75 & & \\
\hline$\geq 25,<30$ & $99(32.8)$ & 3.28 & & \\
\hline$\geq 30$ & $14(4.6)$ & 2.93 & & \\
\hline \multicolumn{5}{|l|}{ Irritable bowel symptom } \\
\hline No & $389(96.0)$ & 2.90 & & $0.325^{\dagger}$ \\
\hline Yes & $16(4.0)$ & 3.50 & & \\
\hline \multicolumn{5}{|l|}{ Gastrointestinal medication } \\
\hline No & $397(98.0)$ & 2.90 & & $0.082^{\dagger}$ \\
\hline Yes & $8(2.0)$ & 4.38 & & \\
\hline \multicolumn{5}{|l|}{ Current other medication } \\
\hline No & $313(77.3)$ & 2.96 & & $0.578^{\dagger}$ \\
\hline Yes & $92(22.7)$ & 2.80 & & \\
\hline \multicolumn{5}{|l|}{ Abdominal operation history } \\
\hline No & $393(97.0)$ & 2.92 & & $0.722^{+}$ \\
\hline Yes & $12(3.0)$ & 3.17 & & \\
\hline \multicolumn{5}{|l|}{ Past colonscopy history } \\
\hline No & $195(48.1)$ & 2.91 & & $0.915^{\dagger}$ \\
\hline Yes & $210(51.9)$ & 2.94 & & \\
\hline \multicolumn{5}{|l|}{ Physician } \\
\hline A & $138(34.1)$ & 2.40 & & $0.006^{\ddagger}$ \\
\hline B & $125(30.9)$ & 3.18 & & \\
\hline C & $142(35.1)$ & 3.21 & & \\
\hline \multicolumn{5}{|l|}{ Bowel preparation } \\
\hline Good & $235(58.0)$ & 2.74 & & $0.059^{\dagger}$ \\
\hline Poor & $170(42.0)$ & 3.19 & & \\
\hline \multicolumn{5}{|l|}{ Difficulty } \\
\hline Easy & $195(48.1)$ & 3.26 & & $0.026^{\ddagger}$ \\
\hline Moderate & $174(43.0)$ & 2.61 & & \\
\hline Hard & $36(8.9)$ & 2.67 & & \\
\hline \multicolumn{5}{|l|}{ Duration (s) } \\
\hline Mean & $455.32 \pm 223.78$ & & -0.082 & $0.099^{*}$ \\
\hline$\leq 7 \mathrm{~min}$ & 232 (57.4) & 3.07 & & $0.148^{\dagger}$ \\
\hline$>7 \mathrm{~min}$ & $172(42.6)$ & 2.73 & & \\
\hline \multicolumn{5}{|l|}{ Additional procedure } \\
\hline No & $281(69.4)$ & 3.03 & & $0.192^{\dagger}$ \\
\hline Yes & $124(30.6)$ & 2.69 & & \\
\hline \multicolumn{5}{|l|}{ Reinsertion group } \\
\hline Group 0 & 83 (20.5) & 4.54 & & $0.000^{\ddagger}$ \\
\hline Group 1 & 77 (19.0) & 3.73 & & \\
\hline Group 2 & 87 (21.5) & 2.85 & & \\
\hline Group 3 & $81(20.0)$ & 1.98 & & \\
\hline Group 4 & 77 (19.0) & 1.47 & & \\
\hline
\end{tabular}

Values are presented as mean \pm standard deviation for continuous variables or number (\%) for binary variables.

${ }^{\star}$ Calculated by Pearson correlation test. ${ }^{\dagger}$ Calculated by independent samples t-test. ${ }^{\ddagger}$ Calculated by one-way analysis of variance. 


\section{General Characteristics and Abdominal Pain after Colonoscopy According to Reinsertion Site}

Post-colonoscopy abdominal pain assessed by NRS was not significantly different depending on age, sex, BMI, presence of irritable bowel symptoms, history of past abdominal operation, history of past colonoscopy, further procedures during the examination, bowel preparation state, use of gastrointestinal (GI) medication, or examination time. However, patients whose procedure was performed by one particular physician had significantly lower pain scores $(\mathrm{P}=0.006)$, and procedures with a difficulty rating of 'easy' had significantly higher pain scores compared with moderate- and hard-difficulty procedures $(\mathrm{P}=0.026)$. Pain scores were also significantly different between reinsertion site groups; patients with proximal reinsertion sites reported significantly less pain, but pain scores were not significantly different between groups 3 and 4 (Table 2).

\section{Logistic Regression Analysis Results}

Variables that showed a meaningful difference in univariate analysis and reported to affect pain in prior studies were subjected to multivariate analysis using logistic regression. Participants who took GI medicine (8 people) were 8.81 times more likely to feel moderate-to-severe pain (NRS 4 or more) than those who did not (odds ratio [OR], 8.81; 95\% confidence interval [CI], 1.146 to $67.811 ; \mathrm{P}=0.037$ ), and the $\mathrm{OR}$ for moderate-to-severe pain was 0.44 when physicians rated the procedure difficulty as moderate compared with easy (95\% CI, 0.242 to 0.784; $\mathrm{P}=0.006$ ). The $\mathrm{OR}$ for moderate-to-severe pain (NRS 4 or more) was 0.48 for group 1 (95\% CI, 0.242 to $0.961 ; \mathrm{P}=0.038$ ), 0.38 for group 2 (95\% CI, 0.194 to $0.735 ; \mathrm{P}=0.004$ ), 0.09 for group 3 (95\% CI, 0.039 to 0.190; $\mathrm{P}=0.000$ ), and 0.03 for group 4 (95\% $\mathrm{CI}, 0.012$ to $0.098 ; \mathrm{P}=0.000$ ) compared with group 0 (control). Moderate-to-severe pain decreased as the reinsertion site became more proximal (linear-by-linear association 76.45 , $\mathrm{P}=0.000$ ) (Table 3).

\section{DISCUSSION}

This randomized controlled study was designed to evaluate the influence of reinsertion site on post-examination pain when performing decompression after colonoscopy. Among general patient characteristics, almost every variable showed no significant difference between the randomly assigned reinsertion groups, with the exception of the colonoscopy duration and the presence of premedication. However, the colonoscopy duration reflected the time taken for reinsertion in the different groups, and the difference associated with the presence of premedication was likely not significant because the numbers of untreated premedication were too small. In comparison with the control group 0 who received no decompression, groups 1 to 4 showed significantly less pain; moreover, the more proximal the decompression site, the less pain was detected. This is in agreement with previous studies. ${ }^{14-16)}$ For example, a study evaluating the use of carbon dioxidewhich make evenly air decompression of whole colon-indicated that post-procedure pain was significantly lower in the carbon dioxide
Table 3. Odds ratio for moderate-to-severe post-colonoscopic pain (numeric rating scale score $\geq 4$ ) by multiple logistic regression

\begin{tabular}{|c|c|c|c|}
\hline Variable & Number & $\begin{array}{c}\text { Odds ratio } \\
\text { (95\% confidence interval) }\end{array}$ & P-value* \\
\hline \multicolumn{4}{|l|}{ Age (y) } \\
\hline$<40$ & 106 & 1.00 & \\
\hline$\geq 40,<60$ & 254 & $0.95(0.545-1.672)$ & 0.870 \\
\hline$\leq 25$ & 44 & $0.37(0.138-0.970)$ & 0.430 \\
\hline \multicolumn{4}{|l|}{ Sex } \\
\hline Male & 247 & 1.00 & \\
\hline Female & 157 & $1.69(1.011-2.835)$ & 0.450 \\
\hline \multicolumn{4}{|c|}{ Irritable bowel symptoms } \\
\hline No & 396 & 1.00 & \\
\hline Yes & 15 & $0.93(0.264-3.251)$ & 0.905 \\
\hline \multicolumn{4}{|c|}{ Gastrointestinal medication } \\
\hline No & 396 & 1.00 & \\
\hline Yes & 8 & $8.81(1.146-67.811)$ & 0.037 \\
\hline \multicolumn{4}{|c|}{ Abdominal operation history } \\
\hline No & 392 & 1.00 & \\
\hline Yes & 12 & $2.30(0.566-9.375)$ & 0.244 \\
\hline \multicolumn{4}{|c|}{ Past colonscopy history } \\
\hline No & 194 & 1.00 & \\
\hline Yes & 210 & $1.06(0.644-1.752)$ & 0.812 \\
\hline \multicolumn{4}{|l|}{ Physician } \\
\hline$A$ & 138 & 1.00 & \\
\hline B & 124 & 2.27 (1.183-4.346) & 0.014 \\
\hline C & 142 & $1.42(0.617-3.276)$ & 0.409 \\
\hline \multicolumn{4}{|l|}{ Bowel preparation } \\
\hline Good & 234 & 1.00 & \\
\hline Poor & 170 & $1.75(0.811-3.773)$ & 0.154 \\
\hline \multicolumn{4}{|l|}{ Difficulty } \\
\hline Easy & 195 & 1.00 & \\
\hline Moderate & 173 & $0.44(0.242-0.784)$ & 0.006 \\
\hline Hard & 36 & $0.64(0.242-1.670)$ & 0.358 \\
\hline \multicolumn{4}{|l|}{ Duration (s) } \\
\hline$<7 \mathrm{~min}$ & 232 & 1.00 & \\
\hline$\geq 7 \min$ & 172 & 1.35 (0.695-2.601) & 0.379 \\
\hline \multicolumn{4}{|c|}{ Additional procedure } \\
\hline No & 280 & 1.00 & \\
\hline Yes & 124 & $0.89(0.458-1.710)$ & 0.715 \\
\hline Reinsertion group & & & $0.000^{\dagger}$ \\
\hline Group 0 & 83 & 1.00 & \\
\hline Group 1 & 77 & $0.48(0.242-0.961)$ & 0.038 \\
\hline Group 2 & 86 & $0.38(0.194-0.735)$ & 0.004 \\
\hline Group 3 & 81 & $0.09(0.039-0.190)$ & 0.000 \\
\hline Group 4 & 77 & $0.03(0.012-0.098)$ & 0.000 \\
\hline
\end{tabular}

Values are presented as number for binary variables.

${ }^{*}$ Calculated by binary logistic regression analysis. ${ }^{\dagger}$ Calculated by linear-by-linear association, value 76.450 .

group compared with the room-air group, ${ }^{21)}$ and a previous study of intestinal decompression using a rectal tube showed that methods that decompress the right colon or the whole colon were most effective for reducing post-procedure pain. Our study suggests that decompression is more effective as the reinsertion site gets closer to the right colon. The vagal mechanosensitive afferent nerves of the proximal colon are thought to have a lower threshold for distension compared with mechanosensory spinal afferent nerves such as the superior and infe- 
rior mesenteric ganglia; this supports the hypothesis that air distention of the proximal colon plays a critical role in abdominal pain after colonoscopy. ${ }^{22-25)}$

As the pain scores between groups 3 and 4 were not significantly different and the odds ratio difference between groups 3 and 2 was large, scope reinsertion up to the transverse colon where the hepatic flexure can be observed seems to be sufficiently beneficial, and reinsertion to the cecum through the ascending colon may not have additional benefit. This result can be used as a guideline for reinsertion decompression until further studies of reinsertion safety can be conducted. It is also notable that in comparison with the control group (group 0: no reinsertion and not to remove air), air decompression of the left colon significantly reduced post-procedure pain.

It was not possible to compare safety between reinsertion sites in this study, as there was no incidence of perforation or bleeding. Thus, reinsertion safety should be determined by future meta-analyses or randomized controlled studies including more subjects.

One limitation of this study was the absence of a procedure guideline to control for differences in the methods or attitudes of the performers; this could affect the results. Univariate analysis revealed significant differences in patient pain scores between performers, and multi-variable analysis through logistic regression also suggested that different performers can influence the occurrence of moderate or severe pain. Moreover, patients experienced more pain after examinations that were rated as 'easy' difficulty by the performers. These results show that in addition to the method of the performer or technical factors, the attitude toward the procedure can influence the result. As the means of specify qualitative standards, disturbance factor of performers could be excluded afterwards. As almost all patients received conscious sedation endoscopy, the reliability of pain evaluation $30 \mathrm{~min}$ utes after the procedure might also be a problem, considering the halflife of the sedative. Because post-procedure abdominal pain is generally most intense immediately after colonoscopy and the memory of this experience is one compliance-lowering factor, the choice to evaluate pain severity soon after the procedure was an evidence-based decision. However, it is unsatisfactory that among the diverse pain-assessment tools available, only NRS-which could be affected by patient consciousness level—-was used. Pain could be evaluated more reliably if a visualized pain scale was used in combination with the NRS. Despite these limitations, this study is significant in that it included a relatively large number of examinees assigned randomly to evaluate the effect of reinsertion sites on decompression, when previous studies of the effectiveness of decompression by means of reinsertion showed inconsistent results. In summary, scope reinsertion to remove air from the intestine effectively to reduces abdominal pain after colonoscopy; reinsertion to the level of the hepatic flexure appears to be most valid, considering factors such as procedure time and risk of comorbidity. Further studies using a standardized examination guideline are needed, and additional studies evaluating the safety of reinsertion with larger numbers of subjects would be beneficial.

\section{CONFLICT OF INTEREST}

No potential conflict of interest relevant to this article was reported.

\section{REFERENCES}

1. National Cancer Center. Cancer statistics. Goyang: National Cancer Center; 2013.

2. National Cancer Center. Cancer statistics. Goyang: National Cancer Center; 2012.

3. Park SM, Chang YJ, Yun YH, Yoo TW, Huh BY, Kwon S. Cost-effectiveness analysis of colorectal cancer screening in Korean general population. J Korean Acad Fam Med 2004;25:297-306.

4. Shim JI, Kim Y, Han MA, Lee HY, Choi KS, Jun JK, et al. Results of colorectal cancer screening of the national cancer screening program in Korea, 2008. Cancer Res Treat 2010;42:191-8.

5. Health Quality Ontario. Screening methods for early detection of colorectal cancers and polyps: summary of evidence-based analyses. Ont Health Technol Assess Ser 2009;9:1-65.

6. Zauber AG, Winawer SJ, O'Brien MJ, Lansdorp-Vogelaar I, van Ballegooijen $\mathrm{M}$, Hankey BF, et al. Colonoscopic polypectomy and longterm prevention of colorectal-cancer deaths. N Engl J Med 2012;366:687-96.

7. Yang HK. Makyeonhan duryeum, daejangnaesikyeng gumsa. Healthchosun. 2015 June 3. Korean.

8. Bae JY. Deajangnaesikyeng gipihaneun eu algoboni. HealthKorea News. 2011 Dec 7. Korean.

9. Lee YC, Wang HP, Chiu HM, Lin CP, Huang SP, Lai YP, et al. Factors determining post-colonoscopy abdominal pain: prospective study of screening colonoscopy in 1000 subjects. J Gastroenterol Hepatol 2006;21:1575-80.

10. Sumanac K, Zealley I, Fox BM, Rawlinson J, Salena B, Marshall JK, et al. Minimizing postcolonoscopy abdominal pain by using $\mathrm{CO}(2)$ insufflation: a prospective, randomized, double blind, controlled trial evaluating a new commercially available $\mathrm{CO}(2)$ delivery system. Gastrointest Endosc 2002;56:190-4.

11. Yamano HO, Yoshikawa K, Kimura T, Yamamoto E, Harada E, Kudou T, et al. Carbon dioxide insufflation for colonoscopy: evaluation of gas volume, abdominal pain, examination time and transcutaneous partial CO2 pressure. J Gastroenterol 2010;45:1235-40.

12. Hsu WF, Hu WH, Chen YN, Lai HH, Chen MK, Chang LC, et al. Carbon dioxide insufflation can significantly reduce toilet use after colonoscopy: a double-blind randomized controlled trial. Endoscopy 2014;46: 190-5.

13. Sajid MS, Caswell J, Bhatti MI, Sains P, Baig MK, Miles WF. Carbon dioxide insufflation vs conventional air insufflation for colonoscopy: a systematic review and meta-analysis of published randomized controlled trials. Colorectal Dis 2015;17:111-23.

14. Lee JG, Vigil H, Leung JW. A randomized controlled trial of total colonic decompression after colonoscopy to improve patient comfort. Am J Gastroenterol 2001;96:95-100.

15. Kim JK, Park JW, Song KS, Kim HJ, Lee IB, Yoon JB, et al. Effectiveness of a rectal tube for relief of pain after colonoscopy. Korean J Gastrointest Endosc 1999;19:41-5. 
16. Steinberg EN, Howden CW. Randomized controlled trial of rectal tube placement for the management of abdominal distension following colonoscopy. Gastrointest Endosc 1997;46:444-6.

17. Jenkins HH, Spencer ED, Weissgerber AJ, Osborne LA, Pellegrini JE. Correlating an 11-point verbal numeric rating scale to a 4-point verbal rating scale in the measurement of pruritus. J Perianesth Nurs 2009;24: $152-5$.

18. Ferreira-Valente MA, Pais-Ribeiro JL, Jensen MP. Validity of four pain intensity rating scales. Pain 2011;152:2399-404.

19. Wong DL, Baker CM. Pain in children: comparison of assessment scales. Okla Nurse 1988;33:8.

20. Hawker GA, Mian S, Kendzerska T, French M. Measures of adult pain: Visual Analog Scale for Pain (VAS Pain), Numeric Rating Scale for Pain (NRS Pain), McGill Pain Questionnaire (MPQ), Short-Form McGill Pain Questionnaire (SF-MPQ), Chronic Pain Grade Scale (CPGS), Short Form-36 Bodily Pain Scale (SF-36 BPS), and Measure of Inter- mittent and Constant Osteoarthritis Pain (ICOAP). Arthritis Care Res (Hoboken) 2011;63 Suppl 11:S240-52.

21. Stevenson GW, Wilson JA, Wilkinson J, Norman G, Goodacre RL. Pain following colonoscopy: elimination with carbon dioxide. Gastrointest Endosc 1992;38:564-7.

22. Andrews PL. Vagal afferent innervation of the gastrointestinal tract. Prog Brain Res 1986;67:65-86.

23. Grundy D. Speculations on the structure/function relationship for vagal and splanchnic afferent endings supplying the gastrointestinal tract. J Auton Nerv Syst 1988;22:175-80.

24. Parkman HP, Ma RC, Stapelfeldt WH, Szurszewski JH. Direct and indirect mechanosensory pathways from the colon to the inferior mesenteric ganglion. Am J Physiol 1993;265(3 Pt 1):G499-505.

25. Ma RC, Szurszewski JH. Modulation by opioid peptides of mechanosensory pathways supplying the guinea-pig inferior mesenteric ganglion. J Physiol 1996;491(Pt 2):435-45. 